\title{
Quantifying interspecific coagulation efficiency of phytoplankton
}

\author{
Jørgen L. S. Hansen ${ }^{1}$, Thomas Kiørboe ${ }^{2, *}$ \\ 'Marine Biological Laboratory, Strandpromenaden 5, DK-3000 Helsinger, Denmark \\ ${ }^{2}$ Danish Institute for Fisheries Research, Charlottenlund Castle, DK-2920 Charlottenlund, Denmark
}

\begin{abstract}
Non-sticky latex beads and sticky diatoms were used as models to describe mutual coagulation between sticky and non-sticky particles. In mixed suspensions of beads and Thalassiosira nordenskjoeldii, both types of particles coagulated into mixed aggregates at specific rates, from which the interspecific coagulation efficiency could be calculated. Stickiness between beads and $T$ nordenskjoeldii was $50 \%$ of that of $T$. nordenskjoeldii in monospecific suspensions, and this ratio remained constant throughout 12 experiments covering 1 order of magnitude variation in the stickiness level of T. nordenskjoeldii. Mutual coagulation between Skeletonema costatum and the non-sticky cells of Ditylum brightwellii also proceeded with half the efficiency of $S$. costatum alone. The latex beads were suitable to be used as 'standard particles' to quantify the ability of phytoplankton to prime aggregation of suspended particles.
\end{abstract}

KEY WORDS: Phytoplankton stickiness $\cdot$ Interspecific coagulation

\section{INTRODUCTION}

Aggregates consisting of live phytoplankton cells are frequently formed during diatom blooms. Sinking rates of these aggregates may exceed those of free, unaggregated cells by orders of magnitude, and the process of aggregation has been acknowledged as the key mechanism behind the massive sedimentation of phytoplankton often occurring subsequent to diatom blooms (Smetacek 1985. Passow 1991, Riebesell 1991, Kiørboe et al. 1994).

One important mechanism of aggregate formation is physical coagulation, which can be described as the physical collision of free, suspended cells and their subsequent adhesion into aggregates (Jackson 1990). The stickiness coefficient, $\alpha$, expresses the probability of adhesion following the collision of 2 single cells, and models of coagulation processes have shown that this property of algae occasionally determines the dynamics of blooms: a bloom of sticky algae cannot exceed a certain density, the critical concentration, where coagulation balances algal growth (Jackson 1990).

·Addressee for correspondence.E-mail: tk@dfu.min.dk
Measurements of phytoplankton stickiness have been made on a number of diatoms grown in cultures (Kiørboe et al. 1990, Kiørboe \& Hansen 1993, Drapeau et al. 1994) and in field and mesocosm experiments (Kiørboe et al. 1994, Dam \& Drapeau 1995), and it has been shown that several diatom species are sticky. Field studies of diatom blooms have confirmed that phytoplankton aggregates indeed form by means of physical coagulation and that the rates and temporal pattern of their sedimentation can be predicted from coagulation theory (Kiorboe et al. 1994). In order to calculate aggregation rates, these studies have considered the phytoplankton community to be of uniform stickiness. However, phytoplankton communities consist of assemblages of species; aggregation occurs between species, and measurements of stickiness of cultured diatoms suggest variation between species which can differ by orders of magnitude (Kiørboe \& Hansen 1993).

Hansen et al. (1995) modelled coagulation of a multispecies bloom by assuming that only certain species were sticky and that sticky species could cause nonsticky species to aggregate. The model showed that interspecific aggregation may cause a fast succession of species. It was assumed that interspecific stickiness 
equals the average of the intraspecific stickiness coefficients. However, the sticking efficiency between different species has never been measured, and it is not clear how stickiness coefficients measured in monospecific suspensions should be applied to multispecies diatom communities.

This study applies coagulation theory to heterogeneous particle assemblages and presents a technique for measuring stickiness between different populations of particles. In a mixture of non-sticky latex beads and cultured diatoms the aggregation rate of each type of particle is measured separately and the stickiness coefficient of interspecific collisions is calculated.

\section{MATERIALS AND METHODS}

Batch cultures of the diatoms Skeletonema costatum, Thalassiosira nordenskjoeldii and Ditylum brightwelli were cultivated in $B_{1}$ culture medium (Hansen 1989) with silicate (25 $\mathrm{mg} \mathrm{l}^{-1}$, or $75 \mathrm{mg} \mathrm{l}^{-1}$ for $D$. brightwelli), at $10^{\circ} \mathrm{C}$ and a light intensity of $60 \mu \mathrm{E} \mathrm{m} \mathrm{m}^{-2} \mathrm{~s}^{-1}$ in a $12 \mathrm{~h}$ light:12 h dark cycle. In all experiments we used cells in exponential growth. Culture samples for measurements of stickiness were 'washed' prior to the experiments in order to remove exopolymeric material from the suspension of cells which may interfere with stickiness measurements (Kiørboe \& Hansen 1993). This was achieved by 2 to 4 times of reverse filtration through a $6 \mu \mathrm{m}$ plankton gauze followed by resuspension in fresh culture media, thereby reducing the volume fraction of old culture medium to less than $1 \%$. Sub-samples were stained with alcian blue to visualise any mucus particles (transparent exopolymeric particles, TEP) present in the samples as described by Kiørboe \& Hansen (1993).

Stickiness of the diatoms was quantified by the use of a couette device (van Duuren 1968) following the procedure described by Kiørboe \& Hansen (1993). Briefly, a couette consists of 2 cylinders, one inside the other. The outer cylinder rotates, and this generates a well-defined laminar shear in the fluid-filled annular gap between the 2 cylinders. The magnitude of the shear can be calculated from the rotation speed and the dimensions of the cylinders. The couettes were sampled at 15 to 20 min intervals and the particle concentrations monitored by an ELZONE 180 (Particle data, Inc.) particle counter equipped with a 120 or 240 orifice tube. The stickiness coefficient, $\alpha$, can be calculated from the exponential decline in particle concentration (C) over time $t$ (Kiørboe et al. 1990)

$$
C_{t}=C_{0} \exp \left(\frac{7.8240 .0 \%}{\pi}\right) t
$$

where $\phi$ is the volume fraction of particles and $\gamma$ is the shear rate $\left(\mathrm{s}^{-1}\right)$ in the couettes. The experiments were conducted in 2 to 4 couettes simultaneously at shear rates of 8 or $10 \mathrm{~s}^{-1}$ over 1 to $3 \mathrm{~h}$ periods. Individual aggregates were examined microscopically after the experiment.

Estimates of stickiness between different types of particles were obtained using the following technique: non-sticky latex beads were added to a suspension of diatoms and the rate at which the beads coagulated was compared with the coagulation rate of cells alone. Latex beads with an average size of $13.34 \mu \mathrm{m}$ were used together with Thalassiosira nordenskjoeldii (19 $\mu \mathrm{m}$ equivalent spherical diameter, ESD). Because the beads were smaller than the cells, it was possible to distinguish the 2 populations of particles on the electronic particle counter (Fig. 1). The decline in their concentrations was followed simultaneously. The beads were counted in a size window ranging from 6 to $15.6 \mu \mathrm{m}$, and the cells in a window ranging from the smallest cell size up to the maximum limit of the $240 \mu \mathrm{m}$ orifice tube. The formation of a dimer composed of 1 cell and 1 bead causes 1 particle to 'disappear' from the lower window, while the formation of a dimer composed of 2 cells causes 1 particle less in the higher window. Thus, cell-bead and cell-cell coagulation was registered as a decline in particle concentration in the lower and the higher size windows, respectively.

First, an experiment was conducted with beads alone, which confirmed that these particles were nonsticky. Next, the effect of the presence of beads on the estimate of cell-cell stickiness was examined. In 1 experiment the coagulation of cells was measured in 2 simultaneously run couettes, 1 containing beads and diatoms and 1 only with diatoms. Two other test experiments were conducted: 4 couettes were run with varying concentrations of beads but with a constant algal concentration and a second series with varying algal concentrations and a constant concentration of beads.

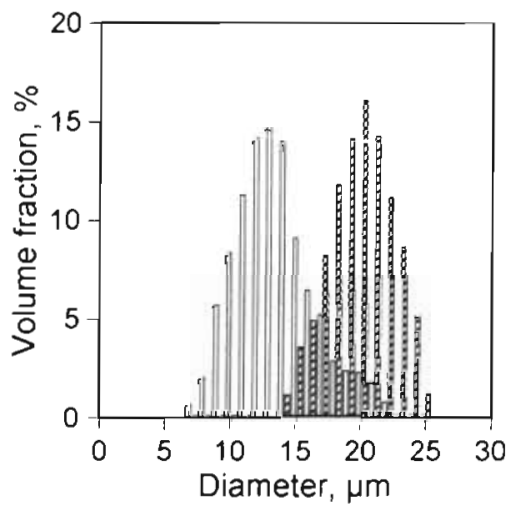

Fig. 1 Thalassiosira nordenskjoeldii. Size distribution of particle volume of latex beads (open bars) and cells of $T$. nordenskjoeldii (hatched bars) 
Following these experiments, another 12 experiments were conducted over a period of 3 mo with $T$. nordenskjoeldii cultures of varying cell-cell stickiness.

Based on the same principles, an experiment was conducted with colonies of Skeletonema costatum (16 $\mu \mathrm{m}$ ESD) together with Ditylum brightwellii (38 $\mu \mathrm{m}$ ESD). Three couettes were run simultaneously, 1 with $S$. costatum ( 4800 colonies $\left.\mathrm{ml}^{-1}\right), 1$ with $D$. brightwelli (800 cells $\mathrm{ml}^{-1}$ ), and 1 containing the 2 species together (each at half the above concentrations). In the 2 couettes containing $S$. costatum, the concentration was monitored only in the size window covering $S$. costatum ( 9 to $30 \mu \mathrm{m}$ ) whereas coagulation of $D$. brightwellii cells alone was followed in the size window from $30 \mu \mathrm{m}$ to the maximum limit of the $240 \mu \mathrm{m}$ orifice tube.

\section{RESULTS}

Staining with alcian blue did not reveal significant amounts of TEP in any of the cultures, and TEP was totally absent in the suspensions of washed cells. The aggregates formed by Thalassiosira nordenskjoeldii in the couette device were dense globules of cells, and they did not absorb stain when exposed to Alcian blue. Thus, there was no indication that TEP had any influence on the coagulation, which agrees with previous studies of Skeletonema costatum (Kiørboe \& Hansen 1993). In monospecific suspensions, vegetative cells of Ditylum brightwellii were consistently non-sticky whereas the stickiness coefficient of T. nordenskjoeldii ranged between 0.1 and 0.7 and S. costatum between 0.1 and 0.6. The control experiment showed that the latex beads themselves were non-sticky.

In mixtures with sticky cells of Thalassiosira nordenskjoeldii, the latex beads coagulated into aggregates, which appeared as a mosaic of beads and cells in the microscope. Due to aggregate formation, the numbers of free cells and latex beads declined exponentially, but at different rates depending on treatment. Parallel experiments run with the same algal concentration but with and without latex beads and with beads in different concentrations showed similar rates of exponential declines of cells (Fig. 2A). The slopes of the individual regressions did not differ significantly (analysis of variance; $0.30>p>0.10$ ) and beads, thus, did not affect measurements of cell-cell stickiness coefficients. In these experiments the coagulation rates of beads were independent of their initial concentration, as indicated by similar slopes $(0.30>p>0.10 ;$ Fig. $2 B)$. In the experiment in which the concentration of cells was varied, coagulation rates of beads followed the coagulation rates of cells (Fig. 2C, D).

The coagulation rate of beads versus coagulation rate of cells in the same couettes revealed a coagulation rate between latex beads and cells of $54 \%$ of that of cells alone. This relative coagulation efficiency remained constant over a variation in coagulation rates spanning 2 orders of magnitude (Fig. $3 \mathrm{~A}$ ) and a variation in stickiness of Thalassiosira nordenskjoeldii of 1 order of magnitude (Fig. 3B). The plots in Fig. 3A and $B$ are equivalent, except that the latter compensates for variation due to variation in particle concentration and shear and reports values as averages $( \pm S D$ ) of replicate couettes.

The experiment with Skeletonema costatum and Ditylum brightwellii revealed a stickiness coefficient of $S$. costatum of 0.54 while $D$. brightwellii did not coagulate in a monospecific suspension. However, $D$. brightwelli appeared in aggregates in the couette containing both species. In the presence of $D$. brightwellii, the rate of decline of particle concentration in the $S$.
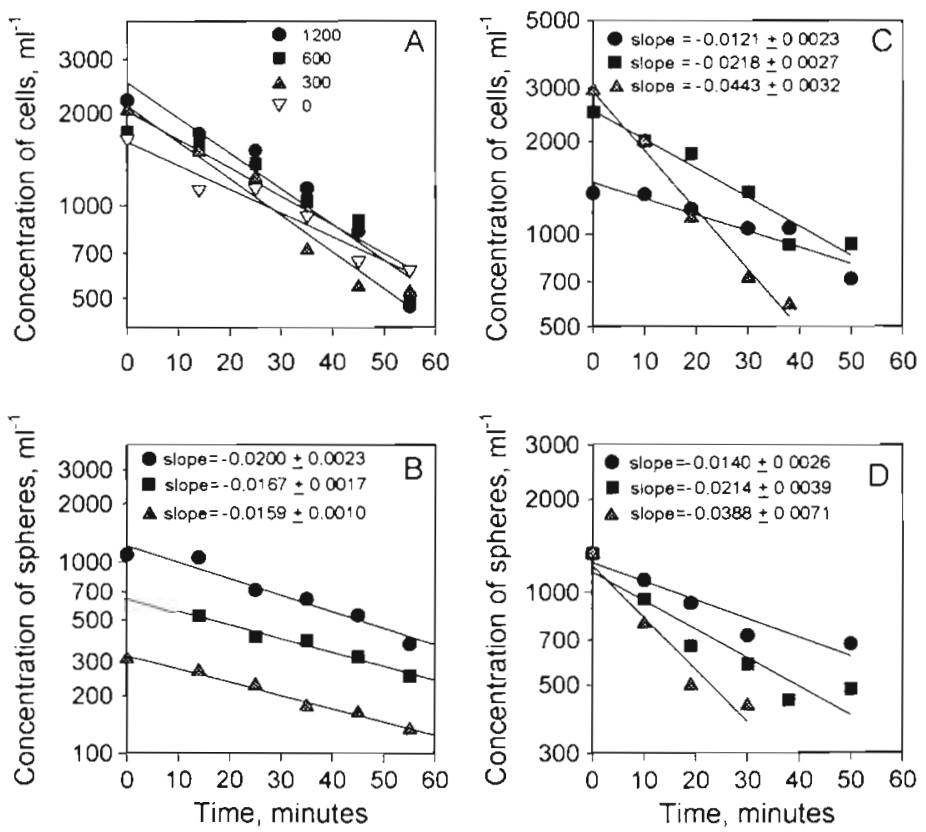

Fig. 2. Thalassiosira nordenskjoeldii. Mutual coagulation between diatoms and latex beads. (A) Cell concentration vs time in a series of 4 simultaneously run couettes all containing the same concentration of cells and beads in varying concentrations $\left(0,300,600\right.$ or $\left.1200 \mathrm{ml}^{-1}\right)$. Estimated slopes ( \pm SD) of the regressions are, in increasing order of bead concentration: $-0.0267 \pm 0.0037 \mathrm{~min}^{-1},-0.0214 \pm 0.0038 \mathrm{~min}^{-1}$, $-0.0274 \pm 0.0028 \mathrm{~min}^{-1},-0.0178 \pm 0.0021 \mathrm{~min}^{-1}$. (B) concentrations of latex beads vs time in the 3 couettes containing spheres in concentrations of 300,600 and $1200 \mathrm{ml}^{-1}$. (C) Cell concentration vs time in a series of 3 couettes with constant bead concentration (1500 $\mathrm{ml}^{-1}$ ) and cells in initial concentrations of 1200,2000 and $3000 \mathrm{ml}^{-1}$ and (D) concentration of beads in the same couettes as (C). All slopes of concentration vs time are obtained from $\log _{e}$-regressions 


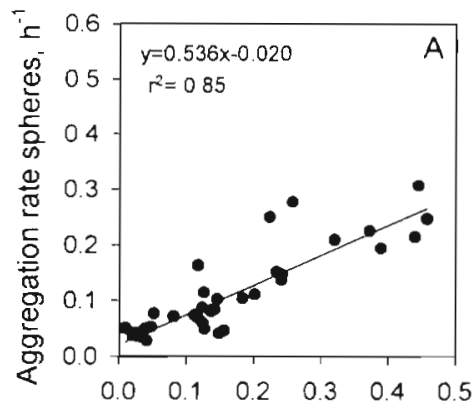

Aggregation rate algae, $h^{-1}$

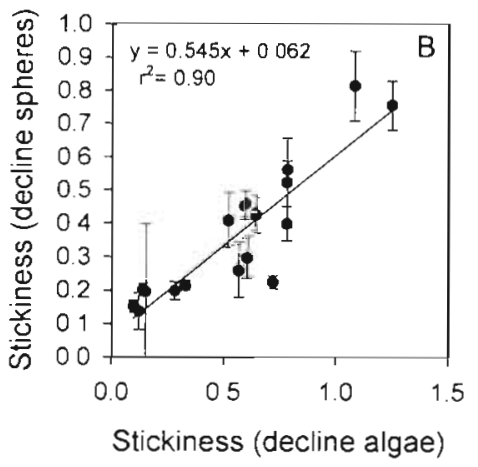

Fig. 3. Thalassiosira nordenskjoeldii. (A) Aggregation rates (= exponential decline in concentration of free particles) of beads vs aggregation rates of $T$. nordenskjoeldii cells measured simultaneously in couettes with mixtures of the 2 types of particles (linear regression: $y=0.536 x-0.0002, r^{2}=0.85, n=$ 34, 1 data point omitted in regression). (B) Stickiness calculated from the exponential decline in bead concentration (according to Eq. 1) vs stickiness calculated from the declining concentration of algae $( \pm \mathrm{SD}$ ), linear regres-

$$
\text { sion: } y=0.545 x+0.062, r^{2}=0.90, n=17
$$

costatum size window was only slightly less than that in the pure suspension of $S$. costatum (Fig. 4), even though the concentration of $S$. costatum was decreased by a factor of 2 . As a consequence, the 'apparent' stickiness coefficient of $S$. costatum, calculated from Eq. (1) and considering only the volume concentration of $S$. costatum, was higher, i.e. 0.94 .

\section{DISCUSSION}

The experiments with the latex beads demonstrate, for the first time, that coagulating diatoms indeed have a sticky surface, which also can prime aggregation of non-

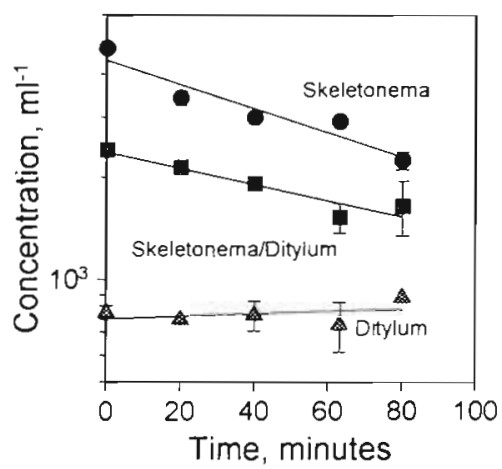

Fig. 4. Skeletonema costatum and Ditylum brightwellij. Particle concentration vs time in a coagulation experiment with monospecific suspensions of $S$, costatum colonies and $D$. brightwellii and the 2 species in a mixture in which only the concentration of $S$. costatum was measured. Error bars indicate standard error of measurements of concentrations (replicate counting). Slopes of $\log _{e}$-regressions are: $S$. costatum: $-0.0189 \pm 0.0036 \mathrm{~min}^{-1}, \mathrm{r}^{2}=0.91, \mathrm{n}=5$. Mixed suspension: $-0.0127 \pm 0.0025 \mathrm{~min}^{-1}, r^{2}=0.89, n=5$ sticky particles, and that diatoms within aggregates are held together by adhesion of frustules. The fact that the cell-bead sticking efficiency strongly relates to the observed cell-cell stickiness supports the conceptual idea of stickiness as a quantifiable property.

It is possible to calculate the sticking efficiency between the Thalassiosira nordenskjoeldii cells and the latex beads. In a monodisperse suspension of particles of diameter $d$, the change in concentration of monomers (C) is (McCave 1984):

$$
\frac{\mathrm{d} C}{\mathrm{~d} t}=-1.3 \alpha \gamma d^{3} C^{2}=-\beta \alpha C^{2}
$$

which is equivalent to Eq. (1) since $\pi d^{3} / 6 C=\phi ; \beta=1.3 \gamma d^{3}$ is the collision kernel for shear coagulation. This equation describes the formation of a dimer as a loss of 1 particle from the suspended population. In order to describe the dynamics of a suspension consisting of 2 populations of particles, a and $b$, having diameters $d_{a}$ and $d_{\mathrm{b}}$, and occurring in concentrations $C_{\mathrm{a}}$ and $C_{\mathrm{b}}$ Eq. (2) expands to

$$
\begin{aligned}
& \frac{\mathrm{d} C}{\mathrm{~d} t}=\frac{\mathrm{d} C_{\mathrm{a}}}{\mathrm{d} t}+\frac{\mathrm{d} C_{\mathrm{b}}}{\mathrm{d} t}= \\
& -\alpha_{\mathrm{a} a} \beta_{\mathrm{a} a} C_{a}^{2}-2 \alpha_{\mathrm{ab}} \beta_{\mathrm{ab}} E_{\mathrm{ab}} C_{\mathrm{a}} C_{b}-\alpha_{\mathrm{bb}} \beta_{\mathrm{bb}} C_{b}^{2}
\end{aligned}
$$

Eq. (3) expresses the loss of particles due to both intraspecific and interspecific coagulation of the populations. In this case, $C_{a}$ and $C_{b}$ describe the total concentration of particles measured in the 2 size windows on the particle counter. The collision kernel for interspecific coagulation is $\beta_{a b}=1.3 \gamma\left(0.5 d_{a}{ }^{3}+0.5 d_{b}{ }^{3}\right)$, and $E_{a b}$ is the contact efficiency between particles of a different size. According to Hill (1992), $E_{\mathrm{ab}}=7.5 p^{2} /$ $(1+2 p)^{2}$, where $p=d_{\mathrm{a}} / d_{\mathrm{b}}$ when $d_{\mathrm{a}}<d_{\mathrm{b}}$. In the present study we used $E_{a b}=9 p^{2} /(1+2 p)^{2}$ because the contact efficiency is included in the measurements of stickiness in monospecific suspensions of algae and $E_{a a}=$ $E_{\mathrm{bb}}=1$ (Hansen et al. 1995)

Since the latex beads (particle a) alone do not coagulate $\left(\alpha_{\mathrm{ad}}=0\right)$, and because interspecific coagulation between algae and latex beads does not affect the concentration of particles larger than or equal to the size of cells (particle b), the decline in each of the particle size windows as monitored on the particle counter is as follows:

$$
\begin{aligned}
& \frac{\mathrm{d} C_{\mathrm{a}}}{\mathrm{d} t}=-2 \alpha_{\mathrm{ab}} \beta_{\mathrm{ab}} E_{\mathrm{ab}} C_{\mathrm{a}} C_{\mathrm{b}} \\
& \frac{\mathrm{d} C_{\mathrm{b}}}{\mathrm{d} t}=-\alpha_{\mathrm{bb}} \beta_{\mathrm{bb}} C_{\mathrm{b}}^{2}
\end{aligned}
$$

The ratio of the specific aggregation rates (or ratios of exponential declines) then equals 


$$
\frac{\left(\frac{\mathrm{d} C_{\mathrm{a}}}{\mathrm{d} t}\right) / C_{\mathrm{a}}}{\left(\frac{\mathrm{d} C_{\mathrm{b}}}{\mathrm{d} t}\right) / C_{\mathrm{b}}}=2 \frac{\alpha_{\mathrm{ab}} \beta_{\mathrm{ab}}}{\alpha_{\mathrm{bb}} \beta_{\mathrm{bb}}}
$$

The observed ratio between the specific aggregation rates of beads and cells was 0.54 (Fig. 3). Inserting the diameters of the latex beads (13.34 $\mu \mathrm{m})$ and cells $\left(19 \mu \mathrm{m}\right.$ ESD) in Eq. (5) results in a ratio of $\alpha_{\mathrm{ab}} / \alpha_{\mathrm{bb}}=0.57$ $\approx 50 \%$. Thus, the interspecific stickiness coefficient between beads and cells equals the average of the intraspecific values.

This may also be true for mutual coagulation of sticky and non-sticky diatoms. Following the basic equations above, it is possible to calculate the interspecific stickiness between the sticky colonies of Skeletonema costatum (species a) and the non-sticky Ditylum brightwelli (species b) from:

$$
\left(\frac{\mathrm{d} C_{\mathrm{a}}}{\mathrm{d} t}\right) / C_{\mathrm{a}}=-\alpha_{\mathrm{aa}} \beta_{\mathrm{aa}} C_{\mathrm{a}}-2 \alpha_{\mathrm{ab}} \beta_{\mathrm{ab}} E_{\mathrm{ab}} C_{\mathrm{b}}
$$

The rate of exponential decline of $S$. costatum in mixture with $D$. brightwelli, $\left(\frac{d C_{0}}{d t}\right) / C_{a}$, was $9.21 \times 10^{-5} \mathrm{~s}^{-1}$ (Fig. 4). Inserting sizes and initial concentrations of the 2 species, the shear rate $\left(10 \mathrm{~s}^{-1}\right)$, and the stickiness coefficient of $S$. costatum ( $\alpha_{a \mathrm{a}}=0.54$ ) into Eq. (6) results in $\alpha_{\mathrm{ab}}=0.24$ or $\alpha_{a b} / \alpha_{a a}=0.44 \approx 50 \%$. Again, the interspecific stickiness equals the average stickiness of the 2 groups of particles. Although this last experiment needs to be repeated with different species, the result suggests that aggregate formation in multi-species blooms may be primed by a few sticky species. The results also verify the assumptions made by Hansen et al. (1995), who used the average stickiness of 2 species to calculate interspecific coagulation. Their models showed that mutual coagulation and sedimentation caused a fast succession within the diatom community. Thus, an understanding of how mutual coagulation works provides insight into the mechanisms driving species succession during diatom blooms and makes laboratory measurements of stickiness in monospecific suspension more useful for modelling multi-species blooms.

The non-spherical shape of most diatom species makes calculations of interspecific collision rates difficult and consequently measured stickiness values really express the combined effect of the hydrodynam-

Editorial responsibility: Otto Kinne (Editor),

Oldendorf/Luhe, Germany ical behaviour of the cells and their stickiness. Taking this problem into consideration, the spherical and nonsticky latex beads provide a suitable 'standard particle' for measuring the ability of the cells to prime coagulation of other particles in general.

Acknowledgement. Thanks are due to Jack Melby and Pia Christensen for their technical assistance.

\section{LITERATURE CITED}

Dam H, Drapeau DT (1995) Coagulation efficiency, organicmatter glues and the dynamics of particles during a phytoplankton bloom in a mesocosm study. Deep Sea Res 42: $111-123$

Drapeau DT, Dam HG, Grenier G (1994) An improved flocculator design for use in practical aggregation experiments. Limnol Oceanogr 39:723-729

Hansen JLS, Timm U, Kiørboe T (1995) Adaptive significance of phytoplankton stickiness with emphasis on the diatom Skeletonema costatum. Mar Biol 123:667-676

Hansen PJ (1989) The red tide dinoflagellate Alexandrium tamerensis: effects on behaviour and growth of tintinnid ciliates. Mar Ecol Prog Ser 53:105-116

Hill PS (1992) Reconciling aggregation theory with observed vertical flux following phytoplankton blooms. J Geophys Res 97:2295-2308

Jackson GA (1990) A model of the formation to marine algal flocks by physical coagulation processes. Deep Sea Res 37:1197-1211

Kiørboe T, Andersen KP, Dam HG (1990) Coagulation efficiency and aggregate formation in marine phytoplankton. Mar Biol 107:235-245

Kiørboe T, Hansen JLS (1993) Phytoplankton aggregate formation: observations of patterns and mechanisms of cell sticking and the significance of exopolymeric material. J Plankton Res 15:993-1018

Kiørboe T, Lundsgaard C, Olesen M, Hansen JLS (1994) Aggregation and sedimentation processes during a spring phytoplankton bloom: a field experiment to test coagulation theory. J Mar Res 52:297-323

McCave IN (1984) Size spectra and aggregation of suspended particles in the deep ocean. Deep Sea Res 31:329-352

Passow U (1991) Species-specific sedimentation and sinking velocities of diatoms. Mar Biol 108:449-455

Riebesell U (1991) Particle aggregation during a diatom bloom. II. Biological aspects. Mar Ecol Prog Ser 69:281-291

Smetacek VS (1985) Role of sinking in diatoms life-history cycles: ecological, evolutionary and geological significance. Mar Biol 84:239-251

van Duuren FA (1968) Defined velocity gradient model flocculator. J Sanit Eng Div Proc Am Soc Civ Eng 94 no SA4: 671-682

Submitted: June 16, 1997; Accepted: October 30, 1997

Proofs received from author(s): November 19, 1997 